\title{
Research on Teaching Practice for Computer Control Technology Course
}

\author{
Guochen NIU, Jinkun WANG \\ Robotics Institute, Civil Aviation University of China, Tianjin, China
}

\begin{abstract}
A comprehensive thematic project is designed for changing the conditon of emphasizing on theory teaching and ignoring the importance of practices in Computer control technology teaching. With DC servo motor speed control system as a thematic project, the contents of each chapter in Computer control technology including mathematical model descriptions, digital controllers design methods, approximating continuous-time controllers, the control system simulation and the hardware system design are related. Integrating theory teaching and engineering practices as the teaching model and transferring from knowledgebased curriculum mode to theory-practice combination curriculum mode, students' learning abilities, practice abilities and innovation abilities can be improved. From the effect of the practical application, it can get better results as the theory knowledge and engineering practices can be combined closely by studying throughout the theoretical knowledge of Computer control technology and emphasizing on engineering practices, which can provide a reference for the teaching of similar courses.
\end{abstract}

KEYWORD: Computer Control Technology; Thematic Project; Speed Control System; Engineering Practice

\section{INTRODUCTION}

Since the 1990s, "Returning of Engineering" was very popular in the US engineering education. Returning engineering education to the original meaning of the education was encouraged [1]. Aalborg University in Denmark studied the course research based on Problem Based Learning (PBL) [2], and the contents of PBL included cognitive learning, cooperative learning and the theorypractice combination projects added in learning contents. The practical experiences proved that students comprehensive abilities can be greatly improved, thus, PBL curriculum mode became the comprehensive curriculum mode widely used in European countries. The academician Peigen Li in Chinese Academy of Engineering pointed that it was needed for engineering education to go to a deeper level of understanding of the role and significance of engineering practice, and proposed new concepts "students' subject consciousness"and "the practical normality consciousness" [3].

The goal of higher engineering education is training advanced engineering and technical personnel who are adapted for project needs. Integration and practice are the developing trends of curriculum reform for higher engineering education in China [4]. As a course of automation core courses, Computer control technology is one with the combination of theory and practice. Therefore, practice-oriented teaching method of Computer control technology is the reform direction of this course.

\section{THE TEACHING SITUATION OF COMPUTER CONTROL TECHNOLOGY}

\subsection{Teacher-centered teaching}

Traditional teaching of Computer control technology is teacher-centered mode on the whole, in which the teacher is in an absolute active position, while students just listen passively. It leads the suppression of students' active learning and the consciousness of independent thinking, and the limitation of the innovative awareness.

\subsection{Systemic lack of course structure arrangement}

The mode of teaching is organized from "component" to "system" in the arrangement of this course traditionally, that is to say, the key issues of Computer control technology are introduced above all, which have more contents, and finally one or two instances of computer control systems are described. In this teaching model, though students 
can better grasp the theory and design knowledge of components of the control system, there are the problems of "see the trees but not the forest". Students lack systematic concepts, overall system design and debugging capabilities. They will encounter difficulties when it comes to associate the various components of the system to become a complete system.

\subsection{Lack correlation between experiments}

Besides taking the basic theory into account, Computer control technology course emphasizes more on the transition to practice and the combination of control theory and engineering practice [5]. Therefore, the practical training is extremely important. Nowadays, most experiments are usually designed for a certain knowledge module, but there is little correlation between the various experiments. Due to the lack of systematic experiments, it is not easy for students to grasp the relevance of knowledge, which may result in their lack of a whole understanding to the course.

\section{THE BASIC IDEA OF TEACHING DESIGN FOR THEMATIC PRACTICALITY IN COMPUTER CONTROL TECHNOLOGY}

To solve these problems, some comprehensive thematic projects are designed for students to get practical exercise. The theme project is designed with DC servo motor speed control system, and it is throughout in various sections of Computer control technology course, such as the descriptions of mathematical model, digital design methods, approximating continuous-time controllers and hardware system design. Students can have the overall understanding on a engineering problem, and it is equivalent that multiple experiments of the courses are associated through a thematic project. It has progressive relationship between these experiments, and previous experiments lay foundations for subsequent experiments. Generally, most of the knowledge involved with the issues has not been taught when laying thematic projects. Students will be more interested in unknown knowledge, and learn in a more targeted way. And their motivation to learn will be improved. The teaching model of closely contact between theoretical courses and engineering practice is adopted to improve students' learning ability, practice and innovation ability.

\section{DETAILED IMPLEMENTATION OF THE THEMATIC PROJECT IN THE CURRICULUM}

\subsection{The thematic project}

The target is to design a speed control system for a permanent magnet brushed DC servo motor.The parameters are shown in Table 1.

Table 1. DC servo motor parameters

\begin{tabular}{|l|l|}
\hline \multicolumn{1}{|c|}{ Parameter } & Value \\
\hline$U_{m} / \mathrm{V}$ & 24 \\
\hline$K_{E} /(\mathrm{mv} /(\mathrm{r} / \mathrm{min}))$ & 4.9 \\
\hline$K_{T} /(\mathrm{mN} \cdot \mathrm{m} / \mathrm{A})$ & 46.8 \\
\hline$R_{m} / \Omega$ & 10.5 \\
\hline$L_{m} / \mu H$ & 940 \\
\hline$J_{m} /(\mathrm{g} . \mathrm{cm} 2)$ & 27 \\
\hline
\end{tabular}

Where, $U_{m}$ represents the voltage of the armature, $K_{E}$ is the back EMF constant, $K_{T}$ represents torque sensitivity, $R_{m}$ represents the equivalent resistance of the rotor winding, $L_{m}$ represents the equivalent inductance of the rotor winding, $J_{m}$ represents rotor inertia.

Specifications:

(1) Get the $S$ transfer function and $Z$ transfer function (with zero-order hold) in the continuous control system and the discrete control system respectively through analyzing and establishing the mathematical model of the motor.

(2) Get the open-loop step response of the motor speed according to the open-loop DC motor characteristics simulation based on MATLAB.

(3) According to digital PID controller based on MATLAB, draw the output response curve whose given value is $R(t)=1000 \times 1(t)$.

(4) Design the hardware circuit based on MPU (Micro Processor Unit), and draw the circuit diagram after selecting electronic components.

(5) Compile and debug the MPU control procedures to achieve the closed-loop DC motor speed control function.

\subsection{Knowledge points associated in the project}

The advantages of the DC motor include wide speed range, simple control and large torque, and the wide range usage in many cases which have high requirements on speed [6]. As a typical case, DC motor speed control has also been widely used in the Computer control technology curriculum [7-10].

In solving the problem(1), the students are required to understand the objectives of the problem. In DC motor speed control system, there are various ways to control the DC motor. Controlling the armature voltage of the motor is the main way to control the speed and direction, that is finding the relationship between the armature voltage balance 
equation and the torque balance equation. Students need to review the knowledge about DC motor model in Electrical machinery and towage course, and list the DC armature voltage balance equation and torque balance equation. Supposing the motor operates under no-load mode, and the damped coefficient is zero. After the Laplace transform, we can get the transfer function as follows:

$$
\omega_{\mathrm{m}}(s)=\frac{K_{\mathrm{T}} U_{\mathrm{m}}(s)}{J_{\mathrm{m}} L_{\mathrm{m}} s^{2}+\left(J_{\mathrm{m}} R_{\mathrm{m}}\right) s+\left(K_{\mathrm{E}} K_{\mathrm{T}}\right)}
$$

Where, $\mathrm{w}_{\mathrm{m}}$ represents motor angular velocity. During the actual system working, PWM (Pulse Width Modulation) is the main way to control motor speed, for the input signal based on the zero-order hold operating mode to the drive amplifier makes the motor run. That is, the certain duty cycle of the PWM signal of last cycle maintains until next cycle comes. The $\mathrm{Z}$ transfer function of the motor under the discrete control system can be gotten by solving the $\mathrm{Z}$ transfer function of the generalized controlled object. The theoretical mathematics about $Z$ transform and computer control system descriptions are also required in this part.

$\mathrm{S}$ transfer function and $\mathrm{Z}$ transfer function of the motor model can be simulated using Simulink when solving problem (2). From the theoretical point of view, the description that DC motor speed is approximately proportional to the armature voltage can be understood deeper. Besides that, students can transform the $\mathrm{Z}$ transfer function to the differential equations between armature voltage and speed, and write $M$ files to achieve open-loop simulation of step response of the motor speed by themselves.All these can be related to the chapter of the digital controller.

PID controllers are still most widely used in industry fields, students can understand deeper by solving problem (3). Firstly, students need to build DC motor speed control system based on PID controller, then adjust the proper proportional integral differential coefficients according to parameter setting rules of the PID controller. Finally, the ideal system output response curve could be gotten. Furthermore, on the basis of understanding the incremental algorithm and the position algorithm, students can write codes to simulate DC motor speed control system in which the design of digital PID controller and the PID parameters setting are needed.

DC motor speed control system hardware design is involved in Problem(4), which mainly contains the overall program design, and detailed circuit schematics design. Among them, the motor speed real-time feedback circuit, the controller chip selection and motor driver chip selection are the key points of the hardware circuit design. This part relates to the input and output channels and interface technology in theoretical teaching, and it can also be combined with MCU courses closely.

Problem(5) is involved in the realization of control system software. Hardware circuit designed in problem(4) is as the carrier and microcontroller program is compiled to control motor speed. The major work that students need to do includes system software design, module unit debugging, system testing and debugging. In the process of software system design, students need to sort out the main function modules of the system, such as speed acquisition module, filter module, algorithm module of controller, output module of controller, status display module, parameter setting module, and sort out the relationships of information transmission between them. Software modules mentioned above are connected into a whole through some basic techniques of MCU, such as timing, interrupt, IO operations, and so on, in the process of module debugging and system debugging.

Important points of Computer control technology course are associated when conduting the thematic project from problem (1) to problem(5) step by step, shown in Figure 1.

In summary, the designed thematic project can not only connect important points of Computer control technology course, but also combine it with Automatic control principle, Electrical machinery and towage, Microcontroller, Sensors, Electronic technology and other courses closely. And students can get practical exercises by simulating the control system using Matlab, designing hardware circuit based on Altium Designer, and programming based on single-chip control system.

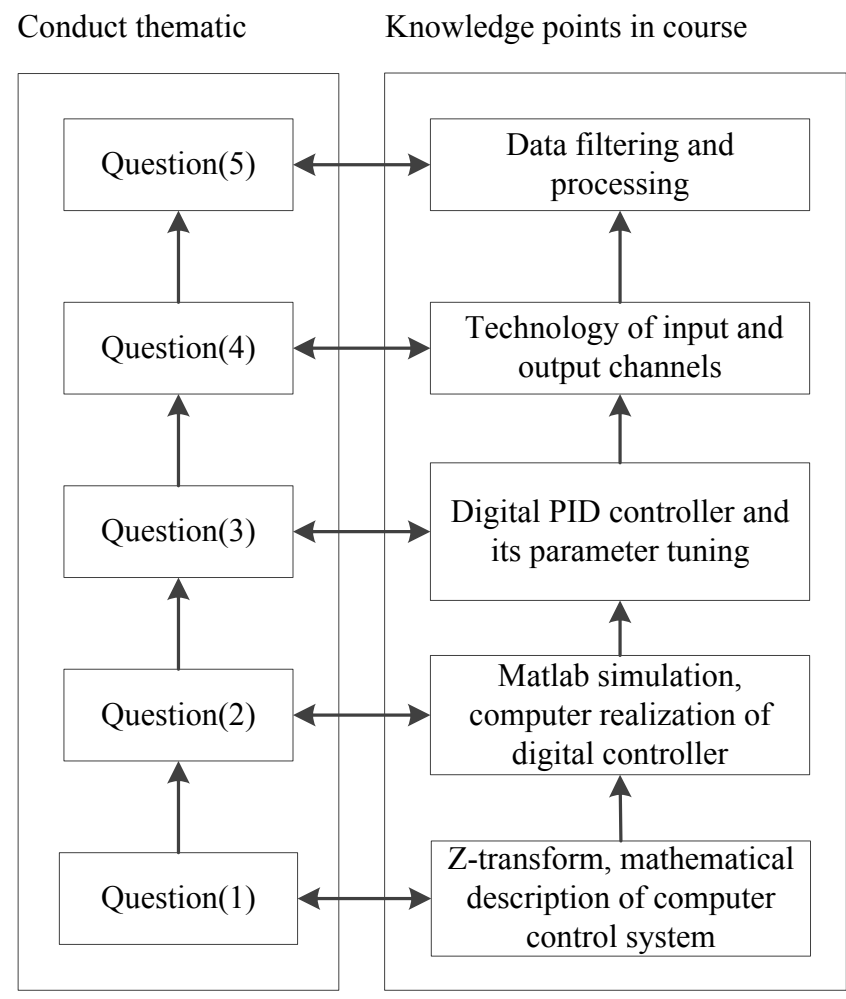

Figure 1. Knowledge points involved in a thematic project 
A typical example is used throughout the curriculum teaching, and it can deepen understanding of the contents for students. The project is integrated into the whole process of the curriculum, and the learning process is to accomplish the project step by step applying theoretical knowledge. Theoretical study and engineering practice are combined by the mode in which theoretical knowledge is learned with cross course project.

\section{CONCLUSIONS}

Thematic project teaching approach of Computer control technology course, where teaching contents are arranged ordered by problems of the thematic project, not only stimulates students' interest in learning and enhances understanding of knowledge points in course, but also improves students' abilities of resolving engineering problems. It fits developing trend of higher engineering education and meets genenal requirements of integrative, pratice and thematic projects. Students who participated in the thematic project also showed better ability of engineering pratice in successive curriculum design and graduation project.

\section{ACKNOWLEDGEMENTS}

This work was funded by Research project of education reform of Civil Aviation University of China CAUC-ETRN-2013-54. The support by Robotics Institute of Civil Aviation University of China is Acknowledged.

\section{REFERENCES}

[1] Gan Junying, Zhang Tingting. Engineering Practice Project: return to the original meaning of engineering. Research in Higher Education of Engineering, 2006, 06:84-88.

[2] Du Xiangyun, Anette Kolmos, Jette Egelund Holgaard. PBL Based Curriculum Innovation for University Teaching and Learning. Research in Higher Education of Engineering, 2009, 03:29-35.

[3] Li Peigen. The Practical Consciousness of the Future Engineering Education. Research in Higher Education of Engineering, 2010, 06:6-8+19.

[4] Sun Jian. Integration and Practicality-A Trend of Curricula Reformation in Higher Engineering Education. Journal of Beijing Institute of Technology (Social Sciences Edition), 2007, 01:110-112.

[5] Lu Feng, Chen Gui, Lin Jian.On the Reform of Special Courses of Control in Characteristic Discipline of Automation-Example of the Curriculum Reform in "Computer Control Technology". China Electric Power Education, 2011, (13):58-60.

[6] Wang Yi, Wang Ping, Su Weida, et al. Design of Control System of DC Motor Based on Digital PID Control. Journal of Fujian Normal University (Natural Science Edition), 2010, 26(7):59-62.

[7] Wang Wei, Wang Donghong. Course Project for Computer-controlled Technology. Journal of Jiangsu University (Higher Education Study Edition), 2003, 25(4):101-103.

[8] Wang Fuxin, Qu Xuelou, Li Shuangfeng. Research and Implementation of Innovative Computer Control Experimental Teaching System. Research and Exploration in Laboratory, 2011, 30(3):77-79.

[9] Wen Shuhui. On Experimentation Teaching Reform of Computer Control Technology. Research in Teaching, 2010, 33(6):59-61.

[10] Zhou Huaan, Zou Xianjun. Development of an Experimental Apparatus for DC Electric Motor Servo Control. Research and Exploration in laboratory, 2004, 23(12):146-147. 